Check for updates

Cite this: J. Mater. Chem. A, 2021, 9, 18773

\section{Designing the electronic and geometric structures of single-atom and nanocluster catalysts}

\author{
Tianxiang Chen, ${ }^{\mathrm{ab}}$ Lin Ye*c and Tsz Woon Benedict Lo (iD *ab \\ This article highlights some recent advances in the electronic and geometric structures of single-atom and \\ nanocluster catalysts, which play an inevitably important role in modern catalysis. The combined use of \\ modern characterisation techniques enables surface, solid-state and coordination chemists to develop \\ more extensive, more cohesive and more appropriate frameworks to rationalise the structure-reactivity \\ functions of these atomically dispersed entities, which further provides the necessary details for the \\ identification of chemical trends and benchmark quantum sciences. We also offer an outlook on the \\ challenges and opportunities of this research area.
}

Received 1st April 2021

Accepted 7th June 2021

DOI: $10.1039 / \mathrm{d} 1 \mathrm{ta} 02723 a$

rsc.li/materials-a where there could be better combinations that exist theoretically. The molecular and catalytic specificities of enzymes come from their unique electronic and geometric (three-dimensional) structures. ${ }^{1,2}$ Thanks to the extensively variable oxidation states, many redox-active enzymes contain mid-to-late $3 \mathrm{~d}$ transition metal ions. The unique electronic (redox of metal centres) and geometric properties (inert protein scaffold) lead to exceptional biological functionality and product specificity in bio-catalysis. The electronic structures of the metal centres are related to the highest occupied molecular orbital-lowest unoccupied molecular orbital (HOMO-LUMO) work functions that control the binding preferences and redox properties; the metal co-factors are optimised to facilitate adsorption and activate the catalytic processes subsequently. In contrast, the geometric properties, such as coordination and surrounding environments of the metal centre(s), confinement and wall effects, can affect the adsorption kinetics, hence regulating the molecular specificity. ${ }^{3}$ A notable example is the $\mathrm{Cu}$ centre in plastocyanin where the $\mathrm{Cu}(\mathrm{II}) / \mathrm{Cu}(\mathrm{I})$ redox couple is facilitated by the pseudo-tetrahedral coordination environment of the $\mathrm{Cu}$ centre where minimal structural reorganisation and rapid electron transfer can be achieved.

The phenomenal cooperative actions between the electronic and geometric structures in many biological species shed light on the design of atomically precise metal-containing co-factors for catalysis. Due to the high surface-to-volume ratio, singleatoms (SAs) and multinuclear nanoclusters (NCs) are highly reactive and exhibit colloidal instability when compared to their bulk counterparts. ${ }^{4,5}$ Researchers have accordingly designed many SA and NC metal-containing inorganic compounds for highly chemo-, regio-, and enantio-selective catalytic processes.

The concept of supported SA and NC chemistry has been long discussed. The progress in the development of modern characterisation techniques, notably aberration-corrected scanning transmission electron microscopy (AC-STEM) and

a Research Assistant Professor at the Hong Kong Polytechnic University. 
extended X-ray absorption fine structure (EXAFS) spectroscopy, has driven the recent blossom in the research of these materials, where these sub-nanometric species can be more reliably determined.

In 1999, Iwasawa et al. determined the structure of atomically dispersed $\mathrm{Pt}$ single-atoms on $\mathrm{MgO}$ by primarily employing EXAFS. $^{6}$ In 2003, a simple cyanide leaching method was proposed by Stephanopoulos et al. for the synthesis of atomically dispersed single-atoms on metal oxide, where the singleatom $\mathrm{Au}, \mathrm{Pt} / \mathrm{CeO}_{2}$ catalysts exhibit much higher catalytic activity toward water-gas shift than $\mathrm{Au}$ and Pt nanoparticles. ${ }^{7}$ During the 1990s-2000s, the role of single-atoms in catalytic reactions was extensively discussed. ${ }^{8-13}$ Isolated $\mathrm{Pd}$ on $\mathrm{Al}_{2} \mathrm{O}_{3}$ and Ir on $\mathrm{MgO}$ have been observed by Lee ${ }^{\mathbf{1 4}}$ and Gates ${ }^{15}$ by AC-STEM. Although Lee et al. proposed that 'single-site catalysts' can effectively promote the catalytic performance, the precise synthesis of well-defined 'single-site catalysts' is still a challenge to be extensively realised in a heterogeneous system. In 2011, Zhang et al. fabricated isolated Pt atoms on an $\mathrm{FeO}_{x}$ support and further introduced the concept of 'single-atom catalysis' to describe the catalysis by SACs. ${ }^{\mathbf{1 6}}$

As for NCs, Cotton first defined the term 'metal atom cluster' after investigating the chemistry of low-valent polynuclear rhenium halides of $\left[\mathrm{Re}_{3} \mathrm{Cl}_{12}\right]^{3-}$ in $1964 . .^{17,18}$ In the following decades, cluster chemistry has made substantial progress. Various transition metal clusters have emerged and exhibited remarkable catalytic potential. ${ }^{\mathbf{1 9 - 2 1}}$ Among them, supported $\mathrm{Cu}$ NCs have received a lot of attention due to their potential in offering a practical solution for the utilisation of methane by selectively oxidising methane molecules to methanol. ${ }^{22-25}$ Microporous materials, such as zeolites and metal-organic frameworks, have been widely employed to encapsulate SAs and NCs thanks to the unique chemical functionality and framework confinement effect. However, to practically realise selective methane oxidation is extremely challenging primarily due to two reasons, (i) the high activation barrier to activate the nonpolar $\mathrm{C}-\mathrm{H}$ bond, and (ii) the difficulty in stabilising methanol at the intermediate step but not over-oxidising to yield $\mathrm{CO}_{2}$. Besides selective methane oxidation, $\mathrm{Cu}$ NCs have also been found useful in various catalytic applications. For example, Solomon et al. reported trinuclear Cu NCs in 1997 and revealed the role of trinuclear copper nanoclusters in the hydroperoxide reduction process. ${ }^{26}$ In 2003 , Schoonheydt et al. reported bis $(\mu-$ oxo)dicopper species encapsulated in ZSM-5 zeolite for the decomposition of NO. ${ }^{27}$ Different zeolite topologies, such as $\mathrm{Y}$ and $M O R$, have also been used to host $\mathrm{Cu}$ NCs for catalytic applications. $^{25,28,29}$

In general, there are two common and effective approaches for the fabrication of these atomically precise species, namely, (1) the conventional inorganic chemistry approach and (2) the solid-state chemistry approach.

Certainly, the inorganic chemistry approach (metal complexes) is well-established, where the electronic and geometric structures of the SAs and NCs can be finely tuned by elemental variation, nuclearity control and ligand design. Through the solid-state approach, SAs and NCs can also be prepared by immobilisation on the surface functionalities of various support materials. ${ }^{\mathbf{3 0 , 3 1}}$ Recent advances in the design and fabrication of SAs and NCs have been focused on their stabilisation against sintering/leaching and achieving a high loading ratio. The successful immobilisation of these species over solid-state supports brings heterogeneous catalysis towards the molecular frontier and delivers substantial impact towards the catalysis and functional materials community. The surface free energy per metal atom increases significantly when the ensemble of nuclearity decreases from bulk to nanoparticles, to the NC and SA level. The high surface free energies from a lowered coordination make the supported SAs and NCs achieve higher chemical reactivity. ${ }^{32}$ In some cases, the assembly of surface metal atoms as NCs is essential to provide an optimal geometry for the activation of substrate molecules with the required surface bond formation. ${ }^{33}$

For these kinetically stable sub-nm species used in catalysis where their surface becomes more dominant, the properties of the chemical bonds on the surface can be altered because of various external microenvironmental factors. ${ }^{3,34}$ The bonding coordination, when compared to that in the bulk, is closely associated with local geometry that is affected by surface relaxation and reconstruction. The electronic properties at the surface can also differ substantially from that of the bulk. For example, the existence of a surface can induce additional electronic states or surface states. ${ }^{35}$ It should be noted that it is challenging to obtain precise atomic information about the local structure, leading to a general lack of understanding of the geometric properties and surface chemistry. Also, the asymmetric coordination to metal or ligand in a crystal can generate higher surface energetic facets that alter the local surface polarity in the structure. ${ }^{36,37}$

The support approach is a realistic alternative in offering extensive possibilities for the rational design and precise control of the electronic and geometric structures of SAs and NCs. The choice of support is critical; the support not only acts as physical carriers to immobilise SAs and NCs but also influences the electronic configurations and local geometric structures, as well as the molecular specificities through steric effects. ${ }^{32}$ Besides some open surface supports (e.g., $\mathrm{TiO}_{2}$ and $\mathrm{MgO}$ ), micro/mesoporous supports (e.g., zeolites and metalorganic frameworks (MOFs)) can additionally provide a relatively inert framework to offer spatial properties..$^{22,38-42}$

The advantages and disadvantages of using metal complexes (homogeneous) and solid-state materials (heterogeneous) for catalysis have long been discussed. ${ }^{35,43,44}$ However, a reliable characterisation of the atomically precise SAs and NCs over solid-state supports was difficult to achieve in the past due to technical limitations, in stark contrast to the more mature characterisation of inorganic metal complexes. The main limitation is that the local electronic and geometric environments of the metal sites (e.g., the coordination of the metal atom, the spatial structure of metal-ligand complexes, etc.) have not been well understood, which hinders the development of this class of highly promising solid-state materials. With the impetus in modern characterisation techniques, even single metal species can now be directly observed using suitable high-resolution electron microscopes. ${ }^{45,46}$ By combining with other advanced 
techniques, a more accurate and precise determination of the atomic and structural parameters can be achieved. (6,47,48 $^{4}$ Researchers can more confidently design sub-nm materials with highly precise atomicity based upon the crucial structural information.

With increasing attention to the atomically precise SAs and NCs with low nuclearity, this perspective article will primarily highlight some recent progress in the fundamental study of their electronic and geometric structures, and their corresponding influence on catalytic science.

\section{Electronic properties}

For species that are in the regime of SAs and multinuclear NCs, their electronic structures approach the atomic/molecular frontier. The classical HOMO-LUMO theory is often considered a more appropriate description of the energetics of SAs and NCs (see Fig. 1), which can be applied to both metal complexes and supported SAs and NCs. ${ }^{49}$ The binding energies and the ligand-field splitting are the two key parameters of the HOMOLUMO work functions of d-metal complexes. ${ }^{50}$ The former is attributed to effective nuclear charges $\left(Z_{\text {eff }}\right)$ as well as oxidation states, ${ }^{51}$ while the latter is related to coordination and interactions between the metal nuclei and the ligands. ${ }^{52}$ The fine adjustment of the HOMO-LUMO work functions, based upon the factors mentioned above, could directly affect the catalytic properties by altering the redox properties and binding strengths to incoming reaction substrates. Consequently, the electronic structures of the metal-containing co-factors can be collectively engineered by varying the elemental nature, nuclearity, topology, and coordination/ligation system.

\section{Through elemental variation}

The effective nuclear charge $\left(Z_{\text {eff }}\right)$ and the outermost electron configuration of different d-metal species are pivotal in governing the electronic structures, leading to notably different redox properties and binding preferences. A slight alternation in the binding energy of reaction substrates and intermediates could notably influence the catalytic properties. In many recent
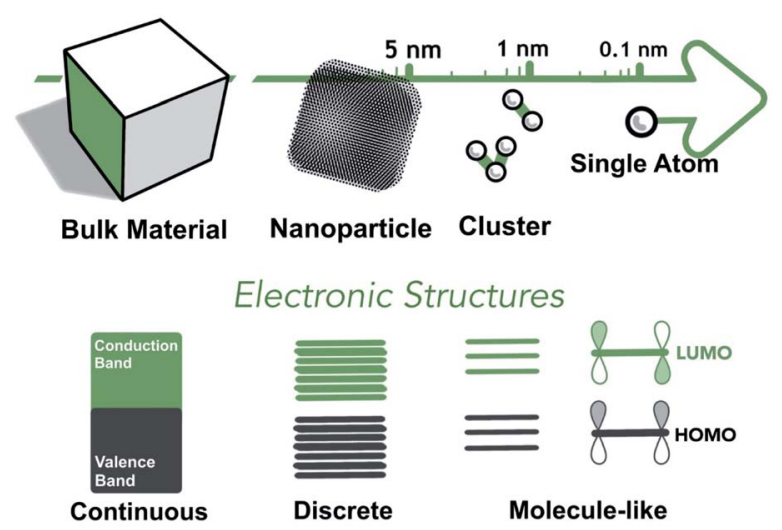

Fig. 1 Electronic and geometric structures of SAs, NCs, nanoparticles, and bulk materials. studies, many catalytic reactions, including $\mathrm{CO}$ oxidation, $\mathrm{CO}_{2}$ reduction, the hydrogen evolution reaction (HER), oxygen evolution reaction (OER), oxygen reduction reaction (ORR), and nitrogen reduction reaction (NRR), have been used as model reactions to probe the electronic structures of SAs due to their more defined adsorbate and intermediate structures. ${ }^{53-59}$ In this sub-section, some strategies to rationalise the electronic structures and catalytic properties as a function of elemental variation will be highlighted.

The electronic structures are often elucidated and expressed in terms of density of states of specific metal sites, based upon simulations. Li et al. have compared the catalytic performance for $\mathrm{CO}$ oxidation with respect to the electronic structures of a series of d-metal SAs ( $\mathrm{Au}, \mathrm{Rh}, \mathrm{Pd}, \mathrm{Co}, \mathrm{Cu}, \mathrm{Ru}$, and $\mathrm{Ti}$ ) supported on iron oxide $\left(\mathrm{FeO}_{x}\right)$ under the Langmuir-Hinshelwood mechanism. ${ }^{60}$ It has been found that the d-band centres of supported Pt, Rh, Pd and Ru SAs were shifted to higher energy when compared to the inactive supported Au SAs. Higher dband metal centres render more empty d states and stronger adsorption interaction with the reaction substrates ( $\mathrm{CO}$ and $\left.\mathrm{O}_{2}\right)$. Yang and co-workers have employed a similar approach to study the relationship between the electronic structures and catalytic activities of a series of SAs (Pd, Fe, Co, and $\mathrm{Ni}$ ) supported on $\gamma-\mathrm{Al}_{2} \mathrm{O}_{3} \cdot{ }^{61} \mathrm{Zheng}$ et al. reported that the conversion of $\mathrm{CO}_{2}$ to $\mathrm{CO}$ is preferred over $\mathrm{Au}, \mathrm{Ag}$ and Pd SA electrocatalysts as they can bind the $\mathrm{COOH}^{*}$ intermediate strongly, but bind $\mathrm{CO}^{*}$ weakly. ${ }^{62}$ Back et al. have predicted the electrochemical $\mathrm{CO}_{2}$ reduction reaction $\left(\mathrm{eCO}_{2} \mathrm{RR}\right)$ properties of a series of SAs on defective graphene based on theoretical calculations, where the electronic interactions between the d-orbital of the SAs and the porbital of graphene govern the density of states and hence the catalytic behaviours. ${ }^{63}$ Also, Li et al. have investigated the electronic structure-reactivity functions of a series of SA M- $\mathrm{N}_{x}$ moieties ( $\mathrm{M}=\mathrm{Mn}, \mathrm{Fe}, \mathrm{Co}, \mathrm{Ni}, \mathrm{Cu})$ with respect to the $\mathrm{eCO}_{2} \mathrm{RR}^{64}$ A volcano trend has been found between their catalytic activities toward CO formation and the nature of the transition metal in $\mathrm{M}-\mathrm{N}_{x}$ sites, with $\mathrm{Fe}$ and Co at the top of the volcano. To correctly model the active sites under in operando conditions, operando Xray absorption near edge structure spectroscopy was performed to study the changes in the metal oxidation state with electrochemical potential. The oxidation states of Co and $\mathrm{Mn}$ remained unchanged with potential, while $\mathrm{Fe}$ and $\mathrm{Ni}$ were partially reduced and $\mathrm{Cu}$ mostly reduced to $\mathrm{Cu}(0) \cdot \mathrm{M}^{2+} \mathrm{N}_{4}-\mathrm{H}_{2} \mathrm{O}$ was identified as the most active centre in $\mathrm{Fe}-\mathrm{N}_{x}$ and $\mathrm{Co}-\mathrm{N}_{x}$, while $\mathrm{Ni}^{1+} \mathrm{N}_{4}$ was predicted to be the most active one in $\mathrm{Ni}-\mathrm{N}_{x}$. The experimental activity and selectivity have been rationalised from the difference between the binding energies for $\mathrm{CO}_{2}{ }^{*}$ and $\mathrm{H}^{*}$ as a descriptor of selectivity toward CO.

The experimental measurements of the electronic structures of supported species have often relied on probing the oxidation states via a study of the metal binding energies. Wu et al. prepared a series of 3d-metal SAs supported on graphene oxide (Fe, Co, Ni and $\mathrm{Cu}$ ). ${ }^{65}$ The electronic structures of these supported SAs were determined by X-ray absorption spectroscopy (XAS), where a charge transfer from the metal to oxygen (M-O bond formation) and the oxidation states of the isolated metal SAs $\mathbf{M}^{\delta+}$ within $0<\delta<3$ have been determined. 

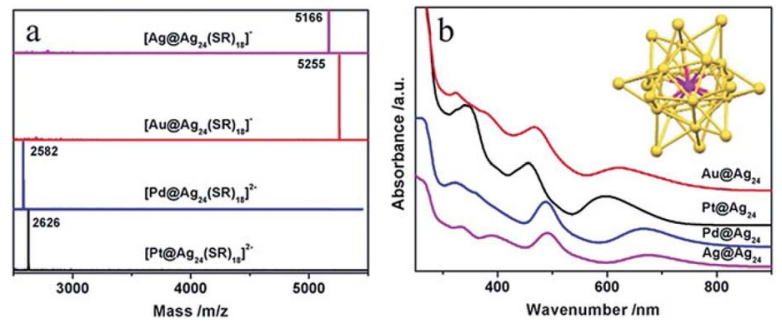

Fig. 2 (a) ESI-MS and (b) UV/vis spectra of $A g @ \mathrm{Ag}_{24}, A u\left(\mathrm{Ag}_{24}\right.$, $\mathrm{Pd} \propto \mathrm{Ag}_{24}$, and Pt@Au $\mathrm{Au}_{24}$ clusters capped by thiolates. Inset: the structural framework of $\mathrm{Au} / \mathrm{Pd} / \mathrm{Pt} / \mathrm{Ag} \mathrm{aAg}_{24}$. $\mathrm{SR}=\mathrm{SPhMe}{ }_{2}$; the $\mathrm{SR}$ moiety is omitted for clarity. ${ }^{67}$ Reprinted with permission from ref. 67. Copyright (2015) American Chemical Society.

Besides oxidation states, the study of the electronic communication via redox hopping between neighbouring SAs can also offer critical information on the catalytic properties, where the extent of necessary electrons supplied can be probed. Xue et al. have employed voltammetric measurements to probe the redox hopping properties of a series of 3d-metal SAs (Fe, Co, $\mathrm{Ni}, \mathrm{Cu}$, and $\mathrm{Zn}$ ) supported on $\mathrm{UiO}-66-\mathrm{NH}_{2} \cdot{ }^{66}$ It has been found that $\mathrm{Cu}^{2+}$ is the most active modifier that allows a rapid electron movement between neighbouring metal sites in the form of $\mathrm{Cu}^{2+} / \mathrm{Cu}^{+}$. It is consistent with their model $\mathrm{eCO}_{2} \mathrm{RR}$ reaction, which has been attributed to the enhanced redox hopping properties, in combination with optimum $\mathrm{CO}^{*}$ binding, that facilitates multielectron $\left(>2 \mathrm{e}^{-}\right)$products.

Bimetallic (or multimetallic) NCs particularly with welldefined alloy structures of noble metals, like $\mathrm{Au}-\mathrm{Ag}, \mathrm{Au}-\mathrm{Cd}$ and $\mathrm{Hg}-\mathrm{Au}$, provide model examples for the influence of elemental composition and electronic structures on catalytic properties. $^{67,68}$ The elemental variation effect has been commonly studied in colloidal species, such as $\mathrm{Au}_{25}$, where $\mathrm{Zhu}$ and co-workers utilised $\mathrm{Au}_{25}(\mathrm{SR})_{18}\left(\mathrm{SR}=\mathrm{SPhMe}_{2}\right)$ as a template to investigate this effect by employing the metal-exchange method. ${ }^{67}$ The doping effect has been investigated with a single foreign atom ( $\mathrm{Au}, \mathrm{Pd}$, or $\mathrm{Pt})$ in the core of an $\mathrm{Ag}_{25} \mathrm{NC}$ on the catalytic properties, where the foreign atom is encapsulated by $24 \mathrm{Ag}$ atoms (Au@ $\mathrm{Ag}_{24}, \mathrm{Pd@Ag}{ }_{24}, \mathrm{Pt} @ \mathrm{Ag}_{24}$ ) (see Fig. 2). ${ }^{69} \mathrm{It}$ has been found that the catalytic performance in the carboxylation reaction of $\mathrm{CO}_{2}$ was influenced substantially due to the alternation in the electronic structures. Also, Kobayashi et al. systematically studied the electronic structures of three bimetallic $\mathrm{Au}-\mathrm{Ag} \mathrm{NCs}$, namely $\mathrm{Au}_{12.2} \mathrm{Ag}_{2.8}, \quad \mathrm{Au}_{14.4} \mathrm{Ag}_{3.6}$, and $\mathrm{Au}_{17.6} \mathrm{Ag}_{7.4}{ }^{68}$ The optical spectroscopy results suggested that the electronic structures of $\mathrm{Au}$ NCs were modulated by the $\mathrm{Ag}$ heteroatoms.

\section{Through nuclearity control}

When compared to typical SAs, multinuclear NCs often show remarkably different catalytic properties because of the general tunability of the electronic and geometric structures. Multinuclear NCs bridge between bulk (classical chemistry) and atomic/ molecular species (quantum chemistry), where the concept of discrete quantum levels in atomic/molecular structures can be

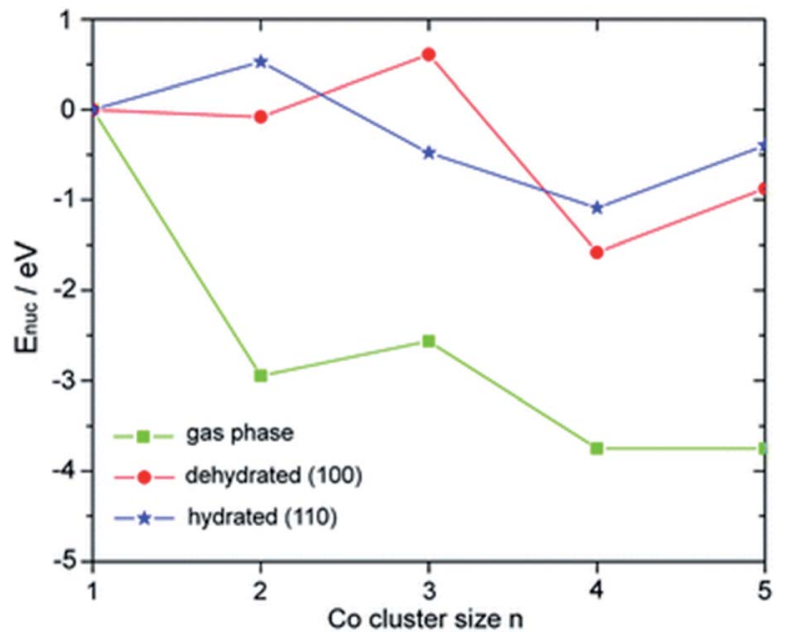

Fig. 3 Nucleation energies $E_{\text {nuc }}$ of $\mathrm{Co}_{n}$ clusters in the gas phase and on the dehydrated (100) and hydrated (110) surfaces. ${ }^{74}$ Reproduced from ref. 74 with permission from The Royal Society of Chemistry.

fine-tuned based on the nuclearity at the active sites. The effect of nuclearity on the electronic structures has been extensively exemplified in various $\mathrm{Au}_{x}$ macro NC structures. ${ }^{\text {70,71 }}$ Meanwhile, atom-by-atom electrodeposition was employed to assemble supported $\mathrm{Pt}_{n}$ and $\mathrm{Co}_{x} \mathrm{O}_{y}$ clusters and the size effect of the cluster has been comprehensively studied in $\mathrm{Pt}_{n}$ (ref. 72) and $\mathrm{Co}_{x} \mathrm{O}_{y}$ clusters. ${ }^{73}$ The size-dependent catalytic performance was evaluated in the HER and OER, respectively. The potential of the HER was shifted positively with increasing size and the OER exhibits a higher relative rate on smaller clusters, where both the minimum-ensemble sized catalysts (i.e., individual Pt and modular $\mathrm{Co}_{1} \mathrm{O}_{x}$ ) show more superior activity than the bulk nanoparticles.

Yang and co-workers have employed first-principles calculations to probe the electronic structures of $\mathrm{Co}_{n}(n=1-5) \mathrm{NCs}$ supported on $\gamma-\mathrm{Al}_{2} \mathrm{O}_{3}$ (100) and (110) surfaces (see Fig. 3), ${ }^{74}$ and $\mathrm{Pd}_{n}(n=1-5)$ NCs supported on rutile $\mathrm{TiO}_{2}$ (100), (001) and (110) surfaces. ${ }^{75}$ It has been found that the stability of the NCs varies as a function of nuclearity and surface support, as the surface binding preferences and nucleation energies of the NCs are notably different. Based upon charge analysis, both metal clusters and support are critical in the charge state of the NCs. The charge of the NCs is highly dependent on the balance between the preferential binding to the surface atoms. The density of states of $\mathrm{Pd}_{n} / \mathrm{TiO}_{2}$ revealed that the $4 \mathrm{~d}$ orbitals of $\mathrm{Pd}$ are close to the Fermi level in some cases (such as $\mathrm{Pd}_{4} / \mathrm{TiO}_{2}$ and $\mathrm{Pd}_{5} / \mathrm{TiO}_{2}$ ), which can be correlated with catalytic activity.

\section{Through metal-support interaction}

As seen in the examples above, the electronic structures of $\mathrm{Co}_{n}$ and $\operatorname{Pd}_{n}$ NCs are affected by their interactions with the supports. ${ }^{74}$ Different local structures of these support substrates could provide alternative coordination environments and electronic correlations. Hence, supports not only act as physical carriers to immobilise the highly reactive SAs and NCs by offering kinetic stabilisation that prevents them from sintering, 

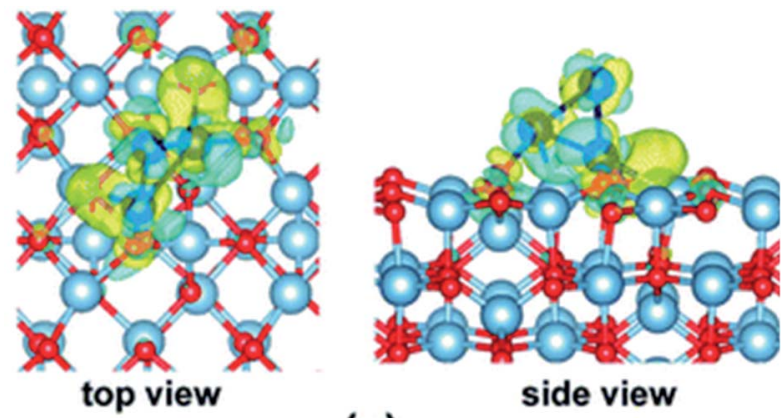

(a)
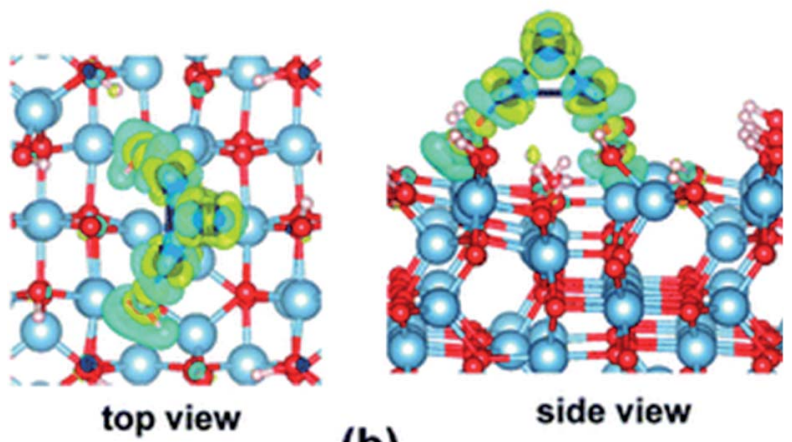

(b)

Fig. 4 Electron density difference maps (isovalue $=0.04$ ) for the $\mathrm{CO}_{3}$ cluster adsorbed on the (a) dehydrated $\gamma-\mathrm{Al}_{2} \mathrm{O}_{3}$ (100) surface and (b) hydrated $\gamma-\mathrm{Al}_{2} \mathrm{O}_{3}(110)$ surface. The charge depletion and accumulation regions are shown in blue and yellow, respectively. ${ }^{74}$ Reproduced from ref. 74 with permission from The Royal Society of Chemistry.

but can also perturb the electronic structures of the supported SAs and NCs through chemical bonding, generally known as metal-support interaction. ${ }^{35,76}$ The metal-support interaction can subtly alter the charge state of the SAs and NCs by electron transfer between SAs and NCs and the support, which can offer activation for reaction substrates and enhance catalytic properties. ${ }^{77}$ As a result, the optimisation of the metal-support interaction by choosing an appropriate support material has attracted great research attention which leads to the rational modification of the electronic structures to achieve more superior catalytic performance. ${ }^{78}$

Yao et al. have engineered the electronic structures of Ru SAs on a series of PtCu alloys via compressive strain to boost the electrocatalytic oxygen evolution reaction. ${ }^{79}$ A volcano relation has been reported between the catalytic activity and the lattice constant of the PtCu alloys. According to density functional theory calculations, the compressive strain of the outer Pt shell can influence the electronic structures of the $\mathrm{Ru}$ SAs, which optimises the binding strengths of oxygen species. As discussed, Yang and co-workers have shown that the electronic structures of $\mathrm{Co}_{3}$ on dehydrated $\gamma-\mathrm{Al}_{2} \mathrm{O}_{3}$ (100) and hydrated $\gamma$ $\mathrm{Al}_{2} \mathrm{O}_{3}$ (110) surfaces are notably different (see Fig. 4). ${ }^{74}$

\section{Through ligand engineering}

One of the most important factors that affect electronic structures is the ligand effect. The ligand-field theory has been well established and can elucidate the electronic structures of dmetal complexes where the key parameters include $\sigma$ bonding, $\pi$-bonding, and the symmetry of the metal centres. There have been extensive research efforts to investigate the electronic structures of d-metal complexes, which offers substantial insight into the subsequent modifications and further design of the supported counterpart for the solid-state community. The ligand effect can promote activation of reaction substrates and provide a mean for activity and selectivity control.

The systematic study of the ligand effect of d-metal complexes is undeniably more mature than that of supported SAs and NCs. Desnoyer et al. systematically studied the electronic structures of a series of square planar $\mathrm{d}^{10} \mathrm{Ni}$ diphosphine $\pi$-complexes that vary as a function of the degree of $\pi$-backbonding of alkene or carbonyl-containing $\pi$-ligand. ${ }^{\mathbf{8 0}}$ The degree of $\pi$-backbonding has been quantitatively correlated between $J$-coupling (from nuclear magnetic resonance (NMR)) and the binding energy of $\mathrm{Ni}$ (from the $1 \mathrm{~s} \rightarrow 4 \mathrm{p}_{z}$ pre-edge in $\mathrm{Ni}$ K-edge X-ray absorption spectroscopy (XAS)), which is determined by the energy of the $\pi^{*}$ ligand acceptor orbital (see Fig. 5). In addition, He et al. have also utilised the binding energy of $\mathrm{Ni}$ ( $\mathrm{Ni}$ L-edge XAS) to quantify the degree of $\pi$-backbonding in a series of $\mathrm{Ni}$ diphosphine $\pi$-complexes. ${ }^{81}$

The influence of ligands on the electronic structures of dmetal inorganic NC complexes has been shown to be similar to those of traditional d-metal complexes. In recent work by Cirri et al., the electronic structures of precise Au NCs with different ligands, namely $\mathrm{Au}_{9}\left(\mathrm{P}(p-\mathrm{X}-\mathrm{Ph})_{3}\right)_{8}{ }^{3+}$ and $\mathrm{Au}_{8}(\mathrm{P}(p-\mathrm{X}-$ $\left.\mathrm{Ph})_{3}\right)_{7}{ }^{2+}$, where $\mathrm{X}$ is $-\mathrm{H},-\mathrm{CH}_{3}$, or $-\mathrm{OCH}_{3}$, at the para position,

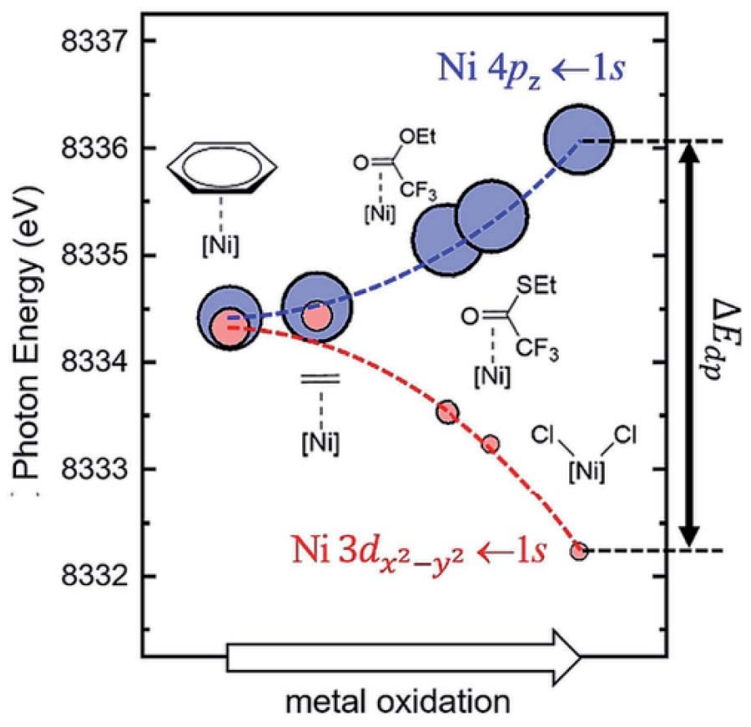

Fig. 5 Calculated Ni K-edge XAS time dependent-DFT results for the pre-edge region of the spectrum. Each complex is represented by

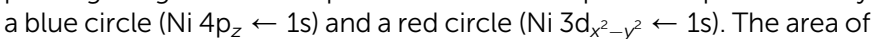
each circle is proportional to the calculated oscillator strength $\left(f_{\text {osc }}\right)$ for each transition. All calculated time dependent-DFT energies at the $\mathrm{Ni}$ K-edge were shifted by $-98.55 \mathrm{eV} .^{80}$ Reproduced from ref. 80 with permission from Wiley, copyright 2019. 
have been elucidated. ${ }^{82}$ The electronic structures have been computed to generalise the unique observation from the mass-selective UV/visible absorption spectra. Using chemical derivatisation, the electronic structures of these complexes are related to the electron-donating or -withdrawing strength of the ligands. Wan et al. have also investigated the ligand effect in catalysis over $\mathrm{Au}_{38}$ NCs with different ligands. ${ }^{83}$

In brief, the ligands can affect the electronic structures of the NCs from two major perspectives, (1) by the manipulation of the energies of the ligand orbitals (which dominates the metal-toligand charge transfer transitions), and (2) by the redistribution of charge density in the NCs (which controls transitions local to the metal core). However, the surface coordination species (or 'ligand') in supported SAs and NCs are more difficult to probe accurately and precisely due to a lack of appropriate techniques from the atomic perspective.

\section{Geometric structures}

Nature is the master architect in designing the geometric structures of SAs and NCs, where metalloprotein is an excellent masterpiece example. Metalloproteins contain metal co-factors at the active sites where the co-factors are surrounded by an extensive pocket of protein scaffold substrates that can offer unique molecular specificities to incoming substrates.

\section{Metal-protein environment in enzymes}

In natural metalloenzymes, the combination of metal nuclei and protein scaffolds is pivotal for the unique activity of enzymes. ${ }^{84}$ Since many transition metals can exist in multiple oxidation states, metalloenzymes usually construct unique environments to immobilise metal ions to allow a minimal structural reorganisation for the redox couples. Adjusting the geometry structures can ensure that the electrons transfer rapidly at the desired metal sites, and specifically targeted molecules can be adsorbed. For example, the $\mathrm{Cu}$ active site in plastocyanin is coordinated with two $\mathrm{N}$ atoms from two histidine residues and an $\mathrm{S}$ atom from cysteine to form a distorted trigonal pyramidal geometry, which leads to a rigid coordination environment for the $\mathrm{Cu}(\mathrm{II}) / \mathrm{Cu}$ (I) redox couple. ${ }^{85}$ In haemoglobin, the pseudo-tetrahedral Fe-containing heme group in the hydrophobic protein pocket can selectively bind $\mathrm{O}_{2}{ }^{86}$ In rubredoxin, the Fe site is coordinated with four cysteine residues forming a pseudo-tetrahedron. ${ }^{87}$ The superoxide dismutase (SOD), Cu,Zn-SOD, contains a binuclear NC co-factor where the $\mathrm{Cu}$ and $\mathrm{Zn}$ sites are bridged by a histidine residue. ${ }^{\mathbf{8}}$ There are also other SOD isozymes that contain Fe, $\mathrm{Mn}$, or Ni metal co-factors. ${ }^{\mathbf{8 9}, 90} \mathrm{Ni}$-SOD is an interesting example as it involves $\mathrm{Ni}$ (III) which is an unusual oxidation state of $\mathrm{Ni}$. The geometry of the $\mathrm{Ni}$ active site transforms between square planar Ni(II), with thiolate (Cys2 and Cys6) and backbone nitrogen (His1 and Cys2) ligands, and square pyramidal Ni(III) with an added axial His1 side-chain ligand. ${ }^{91}$ There are also many other textbook examples, such as carbonic anhydrase and cobalamin. ${ }^{92,93}$ Briefly, the mechanistic discussion of metalloenzymatic activity relies heavily on the elucidation of the interactions between the metal-containing co-factors and the surrounding protein scaffolds, in terms of coordination geometry, coordination number, bonding distances and angles, and so forth.

\section{In metal complexes}

As most enzymes exhibit ultra-high catalytic turnover frequency and product specificity thanks to their optimised electronic and geometric structures, this has inspired the design and development of many inorganic mimicking systems. Taking the artificial particulate form of methane monooxygenase as an example, numerous studies have reported on the design and the subsequent elucidation of the geometric structures with respect to the catalytic properties. For instance, Karlin et al. reported a copper-dioxygen complex mimicking methane monooxygenase, ${ }^{25}$ Stack and co-workers reported a series of $\mathrm{Cu}_{2}$-bis $(\mu$ oxo) (pseudo-trigonal bipyramidal with the $\mathrm{O}$ atoms occupying the axial positions) and $\mathrm{Cu}_{3}$-bis( $\mu$-oxo) complexes, ${ }^{\mathbf{9 4 , 9 5}}$ and Chan and co-workers synthesised a series $\mathrm{Cu}_{3}$ complexes. ${ }^{24,96}$ Another well-studied example is superoxide dismutase mimetics; Fukuzumi et al. reported an imidazolate-bridged $\mathrm{Cu}-\mathrm{Zn}$ binuclear active site model of $\mathrm{Cu}, \mathrm{Zn}$-SOD. ${ }^{97}$ Meanwhile, various Mnbased metal complexes, such as $\mathrm{Mn}$ (III)/(II) porphyrin, ${ }^{98} \mathrm{Mn}$ (II) penta-azamacrocyclic, ${ }^{\mathbf{9 9}}$ and $\mathrm{Mn}$ (III) salen, ${ }^{\mathbf{1 0 0}}$ have been designed as Mn-SOD mimics. ${ }^{101-103}$

There are also many multinuclear NC systems; for instance, Zhang et al. reported a series of related binuclear $\mathrm{Cu}_{2}$ complexes to mimic carboxylesterase. ${ }^{\mathbf{1 0 4}}$ The $\mathrm{Cu}-\mathrm{Cu}$ interatomic distance was determined to be $c a$. $3.0 \AA$, which agrees with the typical $\mathbf{M}-\mathbf{M}$ interatomic distances in most multinuclear NC enzymes. Also, Jiang and co-workers have reported binuclear $\mathrm{Cu}_{2}$ complexes as carboxylesterase mimics which employed an alkoxo/acetato-bridged moiety as a model to promote the hydrolytic cleavage of $p$-nitrophenyl picolinate. ${ }^{105,106}$ Beloglazkina et al. synthesised a mixed-valence $\mathrm{Cu}$ complex with a tridentate $\mathrm{N}_{2} \mathrm{~S}$ type organic ligand as an $\mathrm{N}_{2} \mathrm{O}$ reductase mimic, where it is often regarded as a mimic model for $\mathrm{N}_{2} \mathrm{O}$ reductase. ${ }^{107}$ Generally, the geometric structures about the metalcontaining active sites can be readily elucidated by a combination of single-crystal XRD and spectroscopic techniques (NMR and electron paramagnetic resonance (EPR)). ${ }^{\mathbf{1 0 8 , 1 0 9}}$ The prosperous development of this research area has benignly guided the design of the solid-state counterpart.

\section{Over supported systems}

Two-dimensional metal oxides and porous materials (e.g., zeolites, MOFs, etc.) are great supports to immobilise SAs and NCs, where their topological properties can offer unique molecular specificities to incoming substrates. The recent progress in modern characterisation instrumentation has promoted a more reliable elucidation to allow the subsequent design of supported SA and NC systems in atomic resolution.

Here are many studies on the precise design of supported SAs and NCs in recent years. Notable zeolite-support examples include the trinuclear $\left[\mathrm{Cu}_{3}(\mu-\mathrm{O})_{3}\right]^{2+} \mathrm{NC}$ supported on $\mathbf{M O R}$ zeolite that exhibits a high reactivity towards $\mathrm{C}-\mathrm{H}$ activation of 

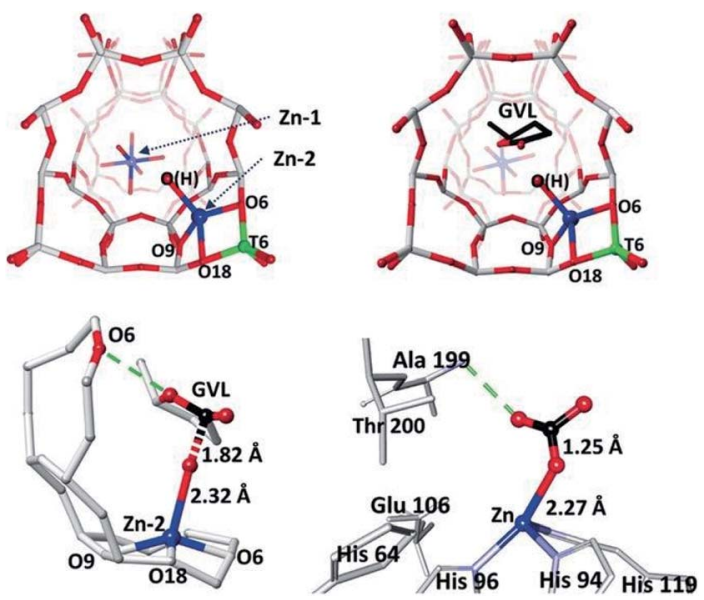

Fig. 6 The refined structures of the $Z n / Z S M-5$ catalyst derived from SXRD and refinements. (a) Zn/ZSM-5; (b) gamma-valerolactone (GVL) adsorbed on Zn/ZSM-5; (c) a close-up view of $\mathrm{Zn}-2-\mathrm{OH}$ interacting with the carbonyl of GVL; (d) a published crystal structure showing a complex intermediate of $\mathrm{Zn}-\mathrm{OH}$ of T199A-CA II enzyme with adsorbed $\mathrm{CO}_{2}$ for comparison (PDB: 1CAM) with permission for reproduction. ${ }^{110}$ Ball-and-stick model: $\mathrm{O}=$ red, $\mathrm{Si}=$ grey, $\mathrm{Al}=$ green, $\mathrm{Zn}=$ blue, and $\mathrm{C}=$ black. Reproduced from ref. 110 with permission from Wiley, copyright 2017.

methane (that mimics methane monooxygenase) by Lercher et $a{ }^{22}$ The structure of the NC was determined by combined XAS analysis and density functional theory (DFT) calculation. The $\left[\mathrm{Cu}_{3}(\mu-\mathrm{O})_{3}\right]^{2+} \mathrm{NC}$ is stabilised by two anionic centres at the entrance of the MOR side pocket. It is proposed that the $\mathrm{C}-\mathrm{H}$ activation can be facilitated by the unique atomic arrangement of the extra-framework $\mathrm{O}$ atoms directed towards the main MOR channel. Tsang et al. have also employed zeolite (MFI type) to host a nucleophilic ' $\mathrm{Zn}-\mathrm{OH}$ ' on the negatively charged framework (see Fig. 6), where the Zn/ZSM-5 catalyst was highly active for the catalytic conversion of $\gamma$-valerolactone to $p$-xylene. ${ }^{\mathbf{1 1 0}}$ The atomic parameters were determined by combined XAS and synchrotron X-ray powder XRD (SXRD). The formation of the framework ' $\mathrm{Zn}-\mathrm{OH}$ ' site has been found to be responsible for the selective decarboxylation of the lactone group to butene through a new hydrolysis pathway, while the adjacent Brønsted acid sites can catalyse the subsequent dimerisation to yield aromatic products. The structure and basic pathway of nucleophilic attack at the terminal $\mathrm{Zn}-\mathrm{OH}$ site are comparable to those of Zn-containing enzymes in biological systems. ${ }^{\mathbf{1 1 0}}$

Recent MOF-supported examples include the binuclear $\mathrm{Cu}_{2}$ co-factor in a Ti-MOF (MIL-125, in the form of $\mathrm{Ti}_{8}-\mathrm{Cu}_{2}$; see Fig. 7) as an efficient artificial monooxygenase by Lin et al. ${ }^{111}$ It was found that the $\mathrm{Cu}_{2}$ site in $\mathrm{Ti}_{8}-\mathrm{Cu}_{2}$ exhibits much higher stability than the mononuclear $\mathrm{Cu}_{1}$ analogue $\left(\mathrm{Ti}_{8}-\mathrm{Cu}_{1}\right)$, which has been attributed to the much promoted catalytic activities to a range of mono-oxidation reactions, such as epoxidation, hydroxylation, Baeyer-Villiger oxidation, and sulphoxidation. Zr-based MOF-808 was employed to post-synthetically install imidazole-based ligand units for subsequent $\mathrm{Cu}(\mathrm{I})$-metalation. The $\mathrm{Cu}$ atoms were found coordinated to $\mathrm{N}$ atoms from imidazole and $\mathrm{O}_{2}$ to form $\mathrm{N}-\mathrm{Cu}_{2} \mathrm{O}_{2}-\mathrm{N}$ species, and the interatomic (a)
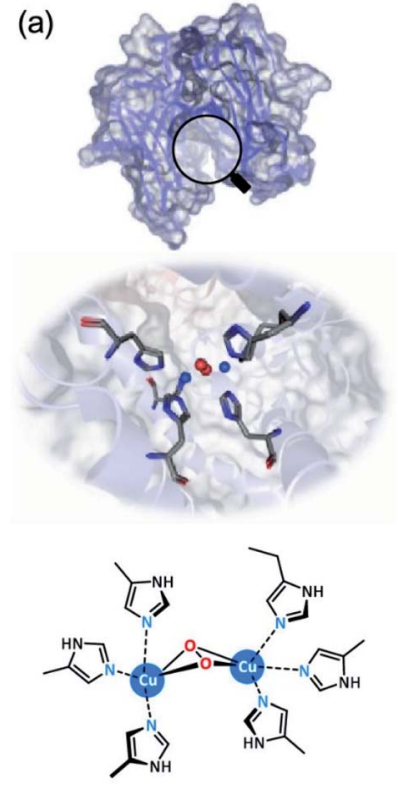

(b)
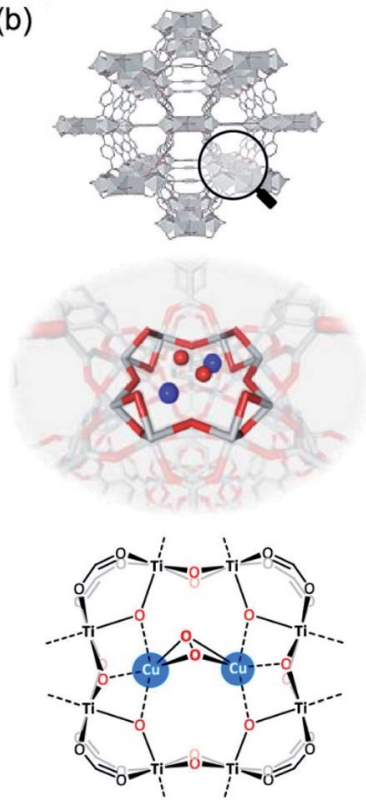

Fig. $7 \mathrm{Cu}_{2}$ active sites with $\mathrm{O}_{2}$ bonding in (a) the natural enzyme tyrosinase (PDB code: $1 \mathrm{WX} 2$ ) and (b) the MOF-based artificial enzyme $\mathrm{Ti}_{8}-\mathrm{Cu}_{2}{ }^{111}$ Reprinted with permission from ref. 111. Copyright (2021) American Chemical Society.

distance between the $\mathrm{Cu}$ sites was found at a distance of $2.51 \AA$ with a coordination number of 0.6 (assigned as bis( $\mu$-oxo) dicopper species). Extra-framework binuclear $\mathrm{Fe}_{2}$ species have also been successfully incorporated into a Zr-based MOF by a post-synthetic exchange method by Ott et al. ${ }^{112}$ The catalyst has high structural similarities to the active site of [FeFe]hydrogenase. From combined single-crystal XRD and XAS analysis, the Fe centres occupy a distorted octahedral geometry with three $\mathrm{C}$ atoms from carbonyl groups and two $\mathrm{S}$ atoms bridging the binuclear $\mathrm{Fe}_{2}$ centre at bond distances of 1.7961.814 and 2.283-2.285 $\mathrm{A}$, respectively. A similar post-synthetic metalation approach has been reported by Bien et al. to generate $\mathrm{Zn}-\mathrm{OH}$ within a $\mathrm{Zn}$-based $\mathrm{MOF}, \mathrm{CFA}-1 .{ }^{113}$ The $\mathrm{Zn}-\mathrm{OH}$ site can promote trace $\mathrm{CO}_{2}$ capture due to the $\mathrm{CO}_{2} / \mathrm{HCO}_{3}{ }^{-}$ chemisorption mechanism and cooperative intercluster $\mathrm{H}$ bonding interactions, which is similar to the secondary coordination sphere interactions in $\alpha$-carbonic anhydrases.

Besides porous materials, the catalytic properties of SAs and NCs can also be modified by interactions with open-surface supports from the modulation of the geometric structures. The syntheses of SAs and NCs on $\mathrm{g}-\mathrm{C}_{3} \mathrm{~N}_{4}$ (ref. 114-116), porous $\mathrm{SiO}_{2}$ (ref. 117 and 118) and carbon-based materials ${ }^{119-122}$ have been shown to offer exciting catalytic performance in many reports. However, it has been challenging to systematically elucidate the geometric structures due to the lack of appropriate characterisation techniques, which hence hinders the establishment of structure-activity relationships.

Comprehensive elucidation of the electronic/geometric structures of SAs and NCs is key to studying their electronic/ geometric structure-activity relationships. Various advanced techniques have been developed for the elucidation of the 
Table 1 A summary of various selected characterisation techniques for the elucidation of the physical characteristics of SAs and NCs

\begin{tabular}{|c|c|c|c|}
\hline Items & Characterisation contents & Examples & Ref. \\
\hline HRTEM & Atomic dispersion & $\mathrm{Pt}$ clusters $/ \gamma-\mathrm{Al}_{2} \mathrm{O}_{3}, \mathrm{Pt} / \mathrm{FeO}_{x}$ & 16 and 125 \\
\hline AC-STEM & Metal particle size distribution & $\mathrm{Pt} @ \mathrm{MCM}-22,0.2 \mathrm{Pt} / m-\mathrm{Al}_{2} \mathrm{O}_{3}$ & 20 and 126 \\
\hline XAS & Oxidation state, bond length, and average coordination numbers & $\mathrm{Pt} / \theta-\mathrm{Al}_{2} \mathrm{O}_{3}, \mathrm{Pt}_{1}{ }^{\delta+} / \mathrm{TiO}_{2}$ & 47 and 129 \\
\hline XPS & Chemical and compositional properties of metal species & $\mathrm{Pt}_{1} @ \mathrm{Fe}-\mathrm{N}-\mathrm{C}, \mathrm{Pt} @ \mathrm{PCM}$ & 130 and 131 \\
\hline UV-vis & Geometric structure & $\mathrm{Cu}_{2}(\mu-\mathrm{O})_{2} / \mathrm{MFI},\left[\mathrm{Cu}_{3}(\mu-\mathrm{O})_{3}\right]^{2+} / \mathrm{MOR}$ & 28 and 132 \\
\hline
\end{tabular}

physical characteristics of SAs and NCs, such as high-resolution transmission electron microscopy (HRTEM), AC-STEM, COabsorbed Fourier-transform infrared spectroscopy (CO-IR), XAS, X-ray photoelectron spectroscopy (XPS), ultraviolet-visible spectroscopy (UV-vis), and SXRD as well as DFT calculation, as summarised in Table 1.

\section{Conclusion and outlook}

In brief, we have summarised some recent advances in the relationships between electronic and geometric structures, and catalytic activity of selected SAs and NCs. The progress in elucidating the electronic and geometric structures using modern characterisation techniques is extraordinary. It has enabled surface, solid-state and coordination chemists to develop more extensive, more cohesive and more appropriate frameworks to rationalise the electronic and geometric structures of these atomically synthesised entities, which further provides the necessary details for the identification of chemical trends and benchmark quantum sciences. ${ }^{70}$

From the extensive collection of studies, it can be seen that the catalytic properties are highly dependent on the electronic and geometric structures of the NCs. On the one hand, the electronic structures are highly related to four key parameters, namely elemental variation, nuclearity control, metal-support interaction, and ligand coordination. They all affect the electronic structures by influencing the HOMO-LUMO work functions that ultimately influence the thermodynamics when the NCs interact with incoming reaction substrates. On the other hand, the geometric structures, as extensively illustrated in multiple examples from metal complexes, enzymes, and over different supported materials, play pivotal roles in providing suitable adsorption configurations and stabilising particular reaction intermediates, as well as affecting the kinetics of catalytic reactions.

We anticipate that the precise synthesis of multi-metallic multinuclear NC active sites with tuneable electronic and geometric structures will be a key future research direction that shares significant coherence with the SA systems. By taking advantage of the synergistic effect between the neighbouring metal nuclei, many long-standing challenges that require the use of more than one catalytic centre can be tackled. For instance, multinuclear NCs can be highly effective catalysts in cross-coupling reactions, due to the presence of multiple neighbouring metal nuclei where reaction substrates can be coadsorbed for the subsequent co-activation. However, it is important to first fill the critical knowledge gap of the difficulty in the atomic design of solid-state catalysts for the control of the structure sensitivity of catalytic reactions.

Although it is well known that the traditional inorganic chemistry approach can enable the precise synthesis of multinuclear complexes, as far as we are aware, directly preparing well-defined NCs on solid-state support materials is inevitably more challenging. This is due to various intrinsic limitations, such as direct metal aggregation and the combination of metal species and multi-basic species that often yield various reticular products.

On the other hand, the characterisation of the electronic and geometric structures will be essential where it is important for the understanding of the structure-reactivity functions. For the elucidation of the supported SAs and NCs, a combination of techniques will be required, depending on the nature of the materials. For instance, for SAs and NCs supported on amorphous materials (such as graphene oxide and amorphous carbon), electron microscopy and XAS have been the two primary techniques to reveal the microenvironment. The lack of long-range order hinders the use of whole-pattern analysis of XRD data to reveal the crystal structure due to the absence of a crystalline phase. In contrast, high-resolution powder XRD can be used to offer essential crystal information of SAs and NCs supported on crystalline support materials (such as zeolites and MOFs). Synchrotron-based XAS and powder XRD techniques, alongside other spectroscopic techniques such as solid-state NMR and EPR, can be combined to determine the coordination information and to elucidate the atomic parameters of supported SAs and NCs. Meanwhile, the Rietveld refinement of powder XRD data can be used to obtain the atomic parameters (to derive the bonding information around the metal sites hereafter), and XAS can provide direct coordination information. We hope that, in the near future, a combination of different in situ/operando synchrotron-based techniques will be applied to further elucidate the structure-reactivity functions, which will consequently make the preparation of more superior SA and NC catalysts more sophisticated and rational. Finally, we provide an outlook of several possible methods based upon our experience that could be effective in the preparation of atomically precise supported NCs where their electronic and geometric structures can be carefully engineered. 
Utilising the chemical and directional functionalities of the templates

A possible preparation method could utilise the inherent molecular chemical, structural and directional specificities of templates such as zeolites and covalent/metal-organic frameworks. The symmetry operations of these templates should aid the preparation of precise NCs by post-synthetic methods. By subsequent treatments, atomically precise NCs could be formed and supported on the framework.

\section{Combining solid-state and coordination chemistries}

Another possible preparation method could be a modular approach that directly utilises the underlying principles of the solid-state and coordination chemistries. Lewis acidic metal ions/complexes and Lewis di-basic linker molecules can be applied in a modular manner, so that electronic and geometric properties can be rationally tuned based upon critical parameters, such as nuclearity control, elemental variation, and ligand design. The use of chiral linker molecules could further result in the formation of peptide-like secondary structures for asymmetric catalysis.

\section{Synergetic catalysis between neighbouring SAs}

The synergetic effect between various neighbouring SAs has been shown to be promising to promote catalytic performance. ${ }^{\mathbf{1 2 3 , 1 2 4}}$ A desirable distribution of active sites, such as Lewis and Brønsted acid sites, with optimal strengths should lead to cooperative and/or tandem reactions. Multiple atomically dispersed SAs within molecular distances could be prepared as a result of a combination of preparation methods.

\section{Conflicts of interest}

There are no conflicts to declare.

\section{Acknowledgements}

This work was supported by the Hong Kong Research Grants Council (15300819 and 25300918), the National Natural Science Foundation of China (21902139), and the Natural Science Fund of Guangdong Province (2021A1515010218) (TWBL).

\section{References}

1 J. R. Knowles, Nature, 1991, 350, 121-124.

2 S. J. Benkovic and S. Hammes-Schiffer, Science, 2003, 301, 1196-1202.

3 T. Chen, Q. Xue, K. C. Leung and B. T. W. Lo, Chem.-Asian J., 2020, 15, 1819-1828.

4 C. Gao, J. Low, R. Long, T. Kong, J. Zhu and Y. Xiong, Chem. Rev., 2020, 120, 12175-12216.

5 J. Cai, R. Javed, D. Ye, H. Zhao and J. Zhang, J. Mater. Chem. A, 2020, 8, 22467-22487.

6 K. Asakura, H. Nagahiro, N. Ichikuni and Y. Iwasawa, Appl. Catal., A, 1999, 188, 313-324.
7 Q. Fu, H. Saltsburg and M. Flytzani-Stephanopoulos, Science, 2003, 301, 935-938.

8 V. Vidal, A. Théolier, J. Thivolle-Cazat and J. M. Basset, Science, 1997, 276, 99-102.

9 C. Lecuyer, F. Quignard, A. Choplin, D. Olivier and J.-M. Basset, Angew. Chem., Int. Ed., 1991, 30, 1660-1661.

10 P. S. Kirlin and B. C. Gates, Nature, 1987, 325, 38-40.

11 E. A. Wovchko and J. T. Yates, J. Am. Chem. Soc., 1998, 120, 10523-10527.

12 S. Abbet, U. Heiz, H. Häkkinen and U. Landman, Phys. Rev. Lett., 2001, 86, 5950-5953.

13 S. Abbet, A. Sanchez, U. Heiz, W. D. Schneider, A. M. Ferrari, G. Pacchioni and N. Rösch, J. Am. Chem. Soc., 2000, 122, 3453-3457.

14 S. F. J. Hackett, R. M. Brydson, M. H. Gass, I. Harvey, A. D. Newman, K. Wilson and A. F. Lee, Angew. Chem., Int. Ed., 2007, 46, 8593-8596.

15 A. Uzun, V. Ortalan, N. D. Browning and B. C. Gates, Chem. Commun., 2009, 4657-4659.

16 B. Qiao, A. Wang, X. Yang, L. F. Allard, Z. Jiang, Y. Cui, J. Liu, J. Li and T. Zhang, Nat. Chem., 2011, 3, 634-641.

17 F. A. Cotton and T. E. Haas, Inorg. Chem., 1964, 3, 10-17.

18 F. A. Cotton, Inorg. Chem., 1964, 3, 1217-1220.

19 L. Liu, M. Lopez-Haro, C. W. Lopes, C. Li, P. Concepcion, L. Simonelli, J. J. Calvino and A. Corma, Nat. Mater., 2019, 18, 866-873.

20 L. Liu, U. Díaz, R. Arenal, G. Agostini, P. Concepción and A. Corma, Nat. Mater., 2017, 16, 132-138.

21 S. Tian, Q. Fu, W. Chen, Q. Feng, Z. Chen, J. Zhang, W. C. Cheong, R. Yu, L. Gu, J. Dong, J. Luo, C. Chen, Q. Peng, C. Draxl, D. Wang and Y. Li, Nat. Commun., 2018, 9, 1-7.

22 S. Grundner, M. A. C. Markovits, G. Li, M. Tromp, E. A. Pidko, E. J. M. Hensen, A. Jentys, M. SanchezSanchez and J. A. Lercher, Nat. Commun., 2015, 6, 1-9.

23 J. Zheng, J. Ye, M. A. Ortuño, J. L. Fulton, O. Y. Gutiérrez, D. M. Camaioni, R. K. Motkuri, Z. Li, T. E. Webber, B. L. Mehdi, N. D. Browning, R. L. Penn, O. K. Farha, J. T. Hupp, D. G. Truhlar, C. J. Cramer and J. A. Lercher, J. Am. Chem. Soc., 2019, 141, 9292-9304.

24 P. P. Y. Chen, R. B. G. Yang, J. C. M. Lee and S. I. Chan, Proc. Natl. Acad. Sci. U. S. A., 2007, 104, 14570-14575.

25 R. A. Himes and K. D. Karlin, Proc. Natl. Acad. Sci. U. S. A., 2009, 106, 18877-18878.

26 U. M. Sundaram, H. H. Zhang, B. Hedman, K. O. Hodgson and E. I. Solomon, J. Am. Chem. Soc., 1997, 119, 1252512540.

27 M. H. Groothaert, J. A. Van Bokhoven, A. A. Battiston, B. M. Weckhuysen and R. A. Schoonheydt, J. Am. Chem. Soc., 2003, 125, 7629-7640.

28 J. S. Woertink, P. J. Smeets, M. H. Groothaert, M. A. Vance, B. F. Sels, R. A. Schoonheydt and E. I. Solomon, Proc. Natl. Acad. Sci. U. S. A., 2009, 106, 18908-18913.

29 P. Vanelderen, R. G. Hadt, P. J. Smeets, E. I. Solomon, R. A. Schoonheydt and B. F. Sels, J. Catal., 2011, 284, 157164. 
30 B. Qiao, A. Wang, X. Yang, L. F. Allard, Z. Jiang, Y. Cui, J. Liu, J. Li and T. Zhang, Nat. Chem., 2011, 3, 634-641.

31 A. Wang, J. Li and T. Zhang, Nat. Rev. Chem., 2018, 2, 65-81. 32 L. Liu and A. Corma, Chem. Rev., 2018, 118, 4981-5079.

33 F. Liao, T. W. B. Lo, J. Qu, A. Kroner, A. Dent and S. C. E. Tsang, Catal. Sci. Technol., 2015, 5, 3491-3495.

34 Q. Xue, Z. Zhang, B. K. Y. Ng, P. Zhao and B. T. W. Lo, Top. Curr. Chem., 2021, 379, 11.

35 W. H. Lai, Z. Miao, Y. X. Wang, J. Z. Wang and S. L. Chou, Adv. Energy Mater., 2019, 9, 1900722.

36 H. T. Kreissl, M. M. J. Li, Y. K. Peng, K. Nakagawa, T. J. N. Hooper, J. V. Hanna, A. Shepherd, T. S. Wu, Y. L. Soo and S. C. E. Tsang, J. Am. Chem. Soc., 2017, 139, 12670-12680.

37 Y. K. Peng, Y. Hu, H. L. Chou, Y. Fu, I. F. Teixeira, L. Zhang, H. He and S. C. E. Tsang, Nat. Commun., 2017, 8, 675.

38 W. Zang, T. Yang, H. Zou, S. Xi, H. Zhang, X. Liu, Z. Kou, Y. Du, Y. P. Feng, L. Shen, L. Duan, J. Wang and S. J. Pennycook, ACS Catal., 2019, 9, 10166-10173.

39 X. Y. Dong, R. Wang, J. Bin Li, S. Q. Zang, H. W. Hou and T. C. W. Mak, Chem. Commun., 2013, 49, 10590-10592.

40 F. Wang, R. M. Yu, X. Y. Wu and C. Z. Lu, Inorg. Chem. Commun., 2012, 19, 70-72.

41 X. Meng, S. Y. Song, X. Z. Song, M. Zhu, S. N. Zhao, L. L. Wu and H. J. Zhang, Chem. Commun., 2015, 51, 8150-8152.

42 C. H. Lee, T. S. Lin and C. Y. Mou, Nano Today, 2009, 4, 165179.

43 X. Cui, W. Li, P. Ryabchuk, K. Junge and M. Beller, Nat. Catal., 2018, 1, 385-397.

44 Q. H. Xia, H. Q. Ge, C. P. Ye, Z. M. Liu and K. X. Su, Chem. Rev., 2005, 105, 1603-1662.

45 J. Jones, H. Xiong, A. T. DeLaRiva, E. J. Peterson, H. Pham, S. R. Challa, G. Qi, S. Oh, M. H. Wiebenga, X. I. P. Hernández, Y. Wang and A. K. Datye, Science, 2016, 353, 150-154.

46 V. Ortalan, A. Uzun, B. C. Gates and N. D. Browning, Nat. Nanotechnol., 2010, 5, 506-510.

47 M. Moses-Debusk, M. Yoon, L. F. Allard, D. R. Mullins, Z. Wu, X. Yang, G. Veith, G. M. Stocks and C. K. Narula, J. Am. Chem. Soc., 2013, 135, 12634-12645.

48 J. Gu, C. S. Hsu, L. Bai, H. M. Chen and X. Hu, Science, 2019, 364, 1091-1094.

49 G. Li, H. Abroshan, C. Liu, S. Zhuo, Z. Li, Y. Xie, H. J. Kim, N. L. Rosi and R. Jin, ACS Nano, 2016, 10, 7998-8005.

50 P. Atkins, T. Overton, J. Rourke, M. Weller and F. Armstrong, Shriver and Atkins' Inorganic Chemistry, Oxford University Press, USA, 2009.

51 G. Silversmit, D. Depla, H. Poelman, G. B. Marin and R. De Gryse, J. Electron Spectrosc. Relat. Phenom., 2004, 135, 167175.

52 J. S. Griffith and L. E. Orgel, Q. Rev., Chem. Soc., 1957, 11, 381-393.

53 Z. Pu, I. S. Amiinu, R. Cheng, P. Wang, C. Zhang, S. Mu, W. Zhao, F. Su, G. Zhang, S. Liao and S. Sun, Nano-Micro Lett., 2020, 12, 1-29.
54 Y. Qu, Z. Li, W. Chen, Y. Lin, T. Yuan, Z. Yang, C. Zhao, J. Wang, C. Zhao, X. Wang, F. Zhou, Z. Zhuang, Y. Wu and Y. Li, Nat. Catal., 2018, 1, 781-786.

55 P. Li, Z. Jin, Y. Qian, Z. Fang, D. Xiao and G. Yu, Mater. Today, 2020, 35, 78-86.

56 D. Qi, Y. Liu, M. Hu, X. Peng, Y. Qiu, S. Zhang, W. Liu, H. Li, G. Hu, L. Zhuo, Y. Qin, J. He, G. Qi, J. Sun, J. Luo and X. Liu, Small, 2020, 16, 2004855.

57 P. Li, Z. Jin, Y. Qian, Z. Fang, D. Xiao and G. Yu, ACS Energy Lett., 2019, 4, 1793-1802.

58 R. Zhang, L. Jiao, W. Yang, G. Wan and H. L. Jiang, J. Mater. Chem. A, 2019, 7, 26371-26377.

59 P. Li, Z. Jin, Z. Fang and G. Yu, Energy Environ. Sci., 2021, 14, 3522-3531.

60 F. Li, Y. Li, X. C. Zeng and Z. Chen, ACS Catal., 2015, 5, 544552.

61 T. Yang, R. Fukuda, S. Hosokawa, T. Tanaka, S. Sakaki and M. Ehara, ChemCatChem, 2017, 9, 1222-1229.

62 W. Zhang, Y. Hu, L. Ma, G. Zhu, Y. Wang, X. Xue, R. Chen, S. Yang and Z. Jin, Adv. Sci., 2018, 5, 1700275.

63 S. Back, J. Lim, N. Y. Kim, Y. H. Kim and Y. Jung, Chem. Sci., 2017, 8, 1090-1096.

64 J. Li, P. Pršlja, T. Shinagawa, A. J. Martín Fernández, F. Krumeich, K. Artyushkova, P. Atanassov, A. Zitolo, Y. Zhou, R. García-Muelas, N. López, J. Pérez-Ramírez and F. Jaouen, ACS Catal., 2019, 9, 10426-10439.

65 Y. Qu, L. Wang, Z. Li, P. Li, Q. Zhang, Y. Lin, F. Zhou, H. Wang, Z. Yang, Y. Hu, M. Zhu, X. Zhao, X. Han, C. Wang, Q. Xu, L. Gu, J. Luo, L. Zheng and Y. Wu, Adv. Mater., 2019, 31, 1904496.

66 Q. Xue, Y. Xie, S. Wu, T. S. Wu, Y. L. Soo, S. Day, C. C. Tang, H. W. Man, S. T. Yuen, K. Y. Wong, Y. Wang, B. T. W. Lo and S. C. E. Tsang, Nanoscale, 2020, 12, 23206-23212.

67 S. Wang, Y. Song, S. Jin, X. Liu, J. Zhang, Y. Pei, X. Meng, M. Chen, P. Li and M. Zhu, J. Am. Chem. Soc., 2015, 137, 4018-4021.

68 R. Kobayashi, Y. Nonoguchi, A. Sasaki and H. Yao, J. Phys. Chem. C, 2014, 118, 15506-15515.

69 W. Hou, Acta Phys.-Chim. Sin., 2019, 35, 453-454.

70 T. Higaki, Y. Li, S. Zhao, Q. Li, S. Li, X. S. Du, S. Yang, J. Chai and R. Jin, Angew. Chem., Int. Ed., 2019, 58, 8291-8302.

71 Y. Du, H. Sheng, D. Astruc and M. Zhu, Chem. Rev., 2020, 120, 526-622.

72 M. Zhou, J. E. Dick and A. J. Bard, J. Am. Chem. Soc., 2017, 139, 17677-17682.

73 Z. Jin and A. J. Bard, Proc. Natl. Acad. Sci. U. S. A., 2020, 117, 12651-12656.

74 T. Yang and M. Ehara, Phys. Chem. Chem. Phys., 2017, 19, 3679-3687.

75 X. Zhao, C. Kong, Z. Yang and T. Yang, ChemistrySelect, 2020, 5, 6939-6945.

76 S. J. Tauster, S. C. Fung and R. L. Garten, J. Am. Chem. Soc., 1978, 100, 170-175.

77 H. Stach, The Surface Science of Metal Oxides, Cambridge University Press, 1995, vol. 191.

78 Y. Yun, H. Sheng, J. Yu, L. Bao, Y. Du, F. Xu, H. Yu, P. Li and M. Zhu, Adv. Synth. Catal., 2018, 360, 4731-4743. 
79 Y. Yao, S. Hu, W. Chen, Z. Q. Huang, W. Wei, T. Yao, R. Liu, K. Zang, X. Wang, G. Wu, W. Yuan, T. Yuan, B. Zhu, W. Liu, Z. Li, D. He, Z. Xue, Y. Wang, X. Zheng, J. Dong, C. R. Chang, Y. Chen, X. Hong, J. Luo, S. Wei, W. X. Li, P. Strasser, Y. Wu and Y. Li, Nat. Catal., 2019, 2, 304-313.

80 A. N. Desnoyer, W. He, S. Behyan, W. Chiu, J. A. Love and P. Kennepohl, Chem.-Eur. J., 2019, 25, 5259-5268.

81 W. He and P. Kennepohl, Faraday Discuss., 2019, 220, 133143.

82 A. Cirri, H. Morales Hernández, C. Kmiotek and C. J. Johnson, Angew. Chem., Int. Ed., 2019, 58, 13818-13822.

83 X. K. Wan, J. Q. Wang, Z. A. Nan and Q. M. Wang, Sci. Adv., 2017, 3, 1701823.

84 A. J. Thomson and H. B. Gray, Curr. Opin. Chem. Biol., 1998, 2, 155-158.

85 M. Seth and T. Ziegler, Adv. Inorg. Chem., 2010, 62, 41-109. 86 N. Abbaspour, R. Hurrell and R. Kelishadi, J. Res. Med. Sci., 2014, 19, 164-174.

87 J. R. Chipperfield, in Encyclopedia of Food Sciences and Nutrition, Elsevier, 2003, pp. 3367-3373.

88 A. K. Boal and A. C. Rosenzweig, Chem. Rev., 2009, 109, 4760-4779.

89 G. E. O. Borgstahl, H. E. Parge, M. J. Hickey, W. F. Beyer, R. A. Hallewell and J. A. Tainer, Cell, 1992, 71, 107-118.

90 J. Wuerges, J. W. Lee, Y. I. Yim, H. S. Yim, S. O. Kang and K. D. Carugo, Proc. Natl. Acad. Sci. U. S. A., 2004, 101, 8569-8574.

91 D. P. Barondeau, C. J. Kassmann, C. K. Bruns, J. A. Tainer and E. D. Getzoff, Biochemistry, 2004, 43, 8038-8047.

92 S. Lindskog, Pharmacol. Ther., 1997, 74, 1-20.

93 M. T. Croft, A. D. Lawrence, E. Raux-Deery, M. J. Warren and A. G. Smith, Nature, 2005, 438, 90-93.

94 A. P. Cole, D. E. Root, P. Mukherjee, E. I. Solomon and T. D. P. Stack, Science, 1996, 273, 1848-1850.

95 C. Citek, B. L. Lin, T. E. Phelps, E. C. Wasinger and T. D. P. Stack, J. Am. Chem. Soc., 2014, 136, 14405-14408.

96 S. I. Chan and S. S. F. Yu, Acc. Chem. Res., 2008, 41, 969-979. 97 H. Ohtsu, Y. Shimazaki, A. Odani, O. Yamauchi, W. Mori, S. Itoh and S. Fukuzumi, J. Am. Chem. Soc., 2000, 122, 5733-5741.

98 B. Gonzalez, J. Kouba, S. Yee, J. F. Kirner and W. R. Scheldt, J. Am. Chem. Soc., 1975, 97, 3247-3249.

99 C. M. Weekley, I. Kenkel, R. Lippert, S. Wei, D. Lieb, T. Cranwell, J. L. Wedding, A. S. Zillmann, R. Rohr, M. R. Filipovic, I. Ivanović-Burmazović and H. H. Harris, Inorg. Chem., 2017, 56, 6076-6093.

100 S. R. Doctrow, K. Huffman, C. B. Marcus, G. Tocco, E. Malfroy, C. A. Adinolfi, H. Kruk, K. Baker, N. Lazarowych, J. Mascarenhas and B. Malfroy, J. Med. Chem., 2002, 45, 4549-4558.

101 M. Baudry, S. Etienne, A. Bruce, M. Paluck, E. Jacobsen and B. Malfroy, Biochem. Biophys. Res. Commun., 1993, 192, 964968.

102 R. O. Costa, S. S. Ferreira, C. A. Pereira, J. R. Harmer, C. J. Noble, G. Schenk, R. W. A. Franco, J. A. L. C. Resende, P. Comba, A. E. Roberts, C. Fernandes and A. Horn, Front. Chem., 2018, 6, 491.
103 I. Batinić-Haberle, J. S. Rebouças and I. Spasojević, Antioxidants Redox Signal., 2010, 13, 877-918.

104 Q. Zhang, J. Shu, Y. Zhang, Z. Xu, J. Yue, X. Liu, B. Xu, Z. Chen and W. Jiang, Dalton Trans., 2020, 49, 10261-10269.

105 W. Jiang, B. Xu, Z. Xiang, S. Huang, F. Liu and Y. Wang, J. Chem. Sci., 2013, 125, 1145-1149.

106 B. Xu, W. Jiang, X. Liu, F. Liu and Z. Xiang, J. Biol. Inorg Chem., 2017, 22, 625-635.

107 A. G. Majouga, E. K. Beloglazkina, A. A. Moiseeva, O. V. Shilova, E. A. Manzheliy, M. A. Lebedeva, E. S. Davies, A. N. Khlobystov and N. V. Zyk, Dalton Trans., 2013, 42, 6290-6293.

108 C. Esmieu, P. Raleiras and G. Berggren, Sustainable Energy Fuels, 2018, 2, 724-750.

109 X. Zhao, S. Q. Zang and X. Chen, Chem. Soc. Rev., 2020, 49, 2481-2503.

110 L. Ye, Q. Song, B. T. W. Lo, J. Zheng, D. Kong, C. A. Murray, C. C. Tang and S. C. E. Tsang, Angew. Chem., Int. Ed., 2017, 56, 10711-10716.

111 X. Feng, Y. Song, J. S. Chen, Z. Xu, S. J. Dunn and W. Lin, J. Am. Chem. Soc., 2021, 143, 1107-1118.

112 S. Pullen, H. Fei, A. Orthaber, S. M. Cohen and S. Ott, J. Am. Chem. Soc., 2013, 135, 16997-17003.

113 C. E. Bien, K. K. Chen, S. C. Chien, B. R. Reiner, L. C. Lin, C. R. Wade and W. S. W. Ho, J. Am. Chem. Soc., 2018, 140, 12662-12666.

114 Z. Zhang, W. Liu, Y. Zhang, J. Bai and J. Liu, ACS Catal., 2021, 11, 313-322.

115 J. Wang, T. Heil, B. Zhu, C. W. Tung, J. Yu, H. M. Chen, M. Antonietti and S. Cao, ACS Nano, 2020, 14, 8584-8593.

116 W. Liu, W. Hu, L. Yang and J. Liu, Nano Energy, 2020, 73, 104750.

117 A. Samanta, B. B. Dhar and R. N. Devi, New J. Chem., 2012, 36, 2625-2629.

118 S. Gao, H. Lin, H. Zhang, H. Yao, Y. Chen and J. Shi, Adv. Sci., 2019, 6, 1801733.

119 L. Huang, J. Chen, L. Gan, J. Wang and S. Dong, Sci. Adv., 2019, 5, eaav5490.

120 F. He, L. Mi, Y. Shen, T. Mori, S. Liu and Y. Zhang, ACS Appl. Mater. Interfaces, 2018, 10, 35327-35333.

121 C. Zhao, C. Xiong, X. Liu, M. Qiao, Z. Li, T. Yuan, J. Wang, Y. Qu, X. Q. Wang, F. Zhou, Q. Xu, S. Wang, M. Chen, W. Wang, Y. Li, T. Yao, Y. Wu and Y. Li, Chem. Commun., 2019, 55, 2285-2288.

122 Y. Wang, Z. Zhang, G. Jia, L. Zheng, J. Zhao and X. Cui, Chem. Commun., 2019, 55, 5271-5274.

123 H. Li, Y. Wen, M. Jiang, Y. Yao, H. Zhou, Z. Huang, J. Li, S. Jiao, Y. Kuang and S. Luo, Adv. Funct. Mater., 2021, 2011289.

124 Y. Wang, M. Li, J. K. Chang, D. Aurelio, W. Li, B. J. Kim, J. H. Kim, M. Liscidini, J. A. Rogers and F. G. Omenetto, Nat. Commun., 2021, 12, 1-9.

125 P. D. Nellist and S. J. Pennycook, Science, 1996, 274, 413415.

126 Z. Zhang, Y. Zhu, H. Asakura, B. Zhang, J. Zhang, M. Zhou, Y. Han, T. Tanaka, A. Wang, T. Zhang and N. Yan, Nat. Commun., 2017, 8, 1-10. 
127 K. Ding, A. Gulec, A. M. Johnson, N. M. Schweitzer, G. D. Stucky, L. D. Marks and P. C. Stair, Science, 2015, 350, 189-192.

128 L. Nie, D. Mei, H. Xiong, B. Peng, Z. Ren, X. I. P. Hernandez, A. DeLaRiva, M. Wang, M. H. Engelhard, L. Kovarik, A. K. Datye and Y. Wang, Science, 2017, 358, 1419-1423.

129 Y. Chen, S. Ji, W. Sun, W. Chen, J. Dong, J. Wen, J. Zhang, Z. Li, L. Zheng, C. Chen, Q. Peng, D. Wang and Y. Li, J. Am. Chem. Soc., 2018, 140, 7407-7410.

130 X. Zeng, J. Shui, X. Liu, Q. Liu, Y. Li, J. Shang, L. Zheng and R. Yu, Adv. Energy Mater., 2018, 8, 1701345.
131 H. Zhang, P. An, W. Zhou, B. Y. Guan, P. Zhang, J. Dong and X. W. Lou, Sci. Adv., 2018, 4, eaao6657.

132 T. Ikuno, S. Grundner, A. Jentys, G. Li, E. Pidko, J. Fulton, M. Sanchez-Sanchez and J. A. Lercher, J. Phys. Chem. C, 2019, 123, 8759-8769.

133 P. Peng, L. Shi, F. Huo, C. Mi, X. Wu, S. Zhang and Z. Xiang, Sci. Adv., 2019, 5, eaaw2322.

134 L. Liu, M. Lopez-Haro, C. W. Lopes, S. Rojas-Buzo, P. Concepcion, R. Manzorro, L. Simonelli, A. Sattler, P. Serna, J. J. Calvino and A. Corma, Nat. Catal., 2020, 3, 628-638. 